\title{
Sobre o intelecto e sua relação com o caráter em Schopenhauer
}

\author{
LÍVIA RIBEIRO LINS *
}

* Mestra em Filosofia pelo PPGFil UFRRJ
RESUMO O intelecto, manifestação da vontade peculiar ao reino animal, de acordo com Schopenhauer, é o produtor das representações, o responsável pela apreensão do mundo pelo sujeito cognoscente. Ele ocupa uma posição secundária, subordinado à vontade e frequentemente empregado nos meios para satisfazer as necessidades impostas por ela. Pelo intelecto o indivíduo é capaz de conhecer e o conhecimento pode ser continuamente modificado na medida em que surgem novas experiências. Não apenas o conhecimento do mundo exterior, mas a consciência de si mesmo é tarefa do intelecto. O caráter individual, inato e imutável, pode se tornar conhecido depois das ações realizadas. Ao observar suas atitudes em certas situações, um indivíduo passa a conhecer seu caráter e a previsão das ações futuras torna-se possível, já que existe a tendência do indivíduo reagir da mesma forma caso o mesmo motivo se apresente. Com o conhecimento da própria individualidade, o intelecto pode formular representações abstratas a fim de direcionar as ações para a utilização de meios diferentes dos que foram empregados anteriormente. Imaginando as consequências para determinados atos, um indivíduo pode agir de outra forma para chegar ao que quer. Diante da impossibilidade de mudança no caráter, o intelecto mostra-se como um fator de grande importância na produção das ações dos indivíduos em seu curso de vida. Busco compreender, neste trabalho, o papel desempenhado pelo intelecto na produção das ações humanas, por sua proporção em relação à vontade ou ao fornecer motivos capazes de direcionar o indivíduo a agir de diferentes formas na busca por seus fins.

PALAVRAS-CHAVE Intelecto; Caráter; Representação. 
O MUNDO como representação tem o sujeito cognoscente como seu sustentáculo. Isso porque, de acordo com Schopenhauer, todo objeto só o é para um sujeito que só pode ser definido dessa maneira em relação ao objeto. Ambos dependem um do outro. A representação é o mundo apreendido pelo sujeito, o que aparece ao indivíduo após a submissão às suas formas de conhecimento. Schopenhauer afirma que "o conjunto do mundo da experiência permanece condicionado, primeiro, pelo conhecimento de um sujeito, que é seu necessário pressuposto. Em seguida, pelas formas especiais de nossa intuição e apreensão" . Os objetos empíricos não são percebidos desvinculados das formas inatas ao sujeito, que são tempo, espaço e causalidade. É no tempo e no espaço que situamos os objetos e os distinguimos dos demais, e a causalidade nos faz perceber que todo efeito deriva de uma causa. A representação pode ser entendida como o resultado de um processo que ocorre no cérebro de todos os animais que tem por fim a geração de uma imagem. Barboza descreve o processo de “confecção das representações":

Ora, a percepção nítida significa a obtenção do resultado final selado de todo aquele processo de construção das coisas, quando o entendimento se serve da causalidade, considera a sensação que lhe foi fornecida como um efeito e, a partir dela, auxiliado pelo tempo, sai à procura da sua causa e, ao chegar nela, serve-se do espaço e a situa; mas agora a causa é um objeto, ou seja, uma imagem construída e presente na consciência ${ }^{2}$.

A percepção por meio das formas inatas ao indivíduo ocorre de forma automática e inconsciente. Se conhecemos as coisas em determinado momento, situadas num certo espaço e sabemos as causas pelas quais ocorrem, não o fazemos com base em dados externos, mas sim pelas formas em que nosso conhecimento é elaborado. O mundo é apreendido pelo sujeito pelas formas do entendimento e não por propriedades das coisas mesmas.

1 SCHOPENHAUER, O mundo como vontade e representação, tomo II, vol.1, p.65.

2 BARBOZA, Schopenhauer: a decifração do enigma do mundo, p.34. 
O intelecto, como parte de um organismo, é manifestação da vontade ${ }^{3}$, e tem o cérebro como seu correspondente físico. Para tornar possível aos animais a percepção do ambiente em que vivem o intelecto foi desenvolvido. "Não foi um intelecto que trouxe a natureza à existência, mas a natureza o intelecto" 4 . De acordo com o filósofo, o intelecto é o maior responsável pelas intuições, ficando os sentidos com a mera sensação. Aos nervos dos órgãos sensoriais cabe a tarefa de emprestar aos objetos cor, som, sabor, temperatura etc.; ao cérebro fica o cargo de proporcionar às coisas tudo o que pode ser representado por tempo, espaço e causalidade, como extensão, forma, solidez e movimento. Para o filósofo, a parte dos sentidos, a de receber impressões, é pequena se compararmos à parte do intelecto, que é a de elaborar as intuições 5 .

A observação de si mais simples e imparcial, associada às conclusões anatômicas, leva ao resultado segundo o qual o intelecto, assim como sua objetivação, o cérebro, e o aparelho sensorial ligado a ele, não é nada senão uma suscetibilidade bem elevada para impressões vindas de fora. Mas o intelecto não constitui nosso ser íntimo, original e próprio. Ele não é, portanto, em nós, aquilo que é a força ativa nas plantas, aquilo que o peso e as energias químicas são na pedra. Só a vontade prova ser tudo isso. Já o intelecto é, em nós, aquilo que na planta pode favorecer ou entravar sua simples suscetibilidade às influências externas, aos efeitos físicos e químicos, a tudo o mais que pode afetar seu crescimento e sua prosperidade 6 .

O intelecto regula as relações do organismo com o mundo externo. Ele é útil para a autopreservação sem interferir diretamente no funcionamento interno do corpo. Sua existência é secundária, servindo de instrumento para que as finalidades volitivas sejam alcançadas.

Mesmo presente em todos os animais o intelecto não é idêntico. Sua capacidade para produzir representações varia nas diferentes espécies e no humano atinge tal grau de complexidade que pode ser diferente entre os indivíduos. Cada homem possui características intelectuais peculiares que fazem com que suas capacidades variem bas-

3 Schopenhauer expõe a noção de vontade como a raiz metafísica do mundo, a coisa-em-si, que se manifesta no mundo corpóreo em diversos graus. Todo fenômeno é manifestação da vontade e esses fenômenos podem ser apreendidos por nós como representação.

4 SCHOPENHAUER, Sobre a vontade na natureza, p.89

5 Cf. SCHOPENHAUER, O mundo como vontade e representação, tomo II, vol.1 p.66, 67.

6 SCHOPENHAUER, Sobre a filosofia e seu método (Parerga e paralipomena), p.83, 84. 
tante. Schopenhauer afirma que o intelecto pode apresentar-se em inúmeros graus de perfeição. Há graus de excitação, que vão da sonolência ao humor e inspiração, e graus de natureza, que se elevam desde os pequenos animais que percebem obscuramente até o homem, em que há variações do imbecil ao gênio7. "Um cérebro pequeno, de inferior conformação, em um crânio espesso" ${ }^{8}$ geralmente abriga um intelecto fraco, enquanto um cérebro de tamanho e desenvolvimento anormais, largo e alto, profundidade inferior e preponderância anormal em relação ao cerebelo, são características do cérebro de um gênio ${ }^{9}$. Schopenhauer indica que a relação entre intelecto e vontade diferencia o homem comum do gênio. O filósofo afirma que "se a pessoa normal consiste em dois terços de vontade e em um terço de intelecto, o gênio, ao contrário, tem dois terços de intelecto e um terço de vontade”ı.

A constituição da maioria dos homens só os permite a preocupação com “comer, beber e copular"11. Seus intelectos permanecem ligados à vontade, o que faz com que sua visão das coisas esteja restrita a vantagens e desvantagens. O homem comum conhece a partir de seus interesses. Ele está voltado para o particular, para o que pode ser útil à manutenção de sua existência. Alguém com excedente de intelecto vê as coisas mesmas desvinculadas de seus interesses pessoais. Esse sujeito é capaz de ver nas coisas o universal, em detrimento de seus interesses. Como seu intelecto fugiu à regra natural de submissão à vontade, frequentemente, não lida bem com coisas particulares o que o leva a ter um curso de vida mais desajeitado, pois "o conhecimento de sua vantagem ou desvantagem fica obscurecido ou até mesmo suprimido"12.

Somente quando se destaca de sua raiz, o intelecto torna-se capaz de uma apreensão puramente objetiva do mundo, pois a vontade opõe-se ao que não está relacionado aos seus próprios objetivos ${ }^{13}$. No entanto, esse é um acontecimento raro. No homem comum, a proporção entre intelecto e vontade não favorece esse desvencilhamento que possibilita

7 Cf. SCHOPENHAUER, O mundo como vontade e representação, tomo II, vol.1, p.314, 315.

8 Idem, p.310.

9 Cf. SCHOPENHAUER, O mundo como vontade e representação, tomo II, vol.2, p.52.

10 Idem, p.33.

11 SCHOPENHAUER, Sobre a filosofia e seu método (Parerga e paralipomena), p.109, nota 27.

12 SCHOPENHAUER, Sobre a filosofia e seu método (Parerga e paralipomena), p.110, nota 27.

13 Cf. SCHOPENHAUER, O mundo como vontade e representação, tomo II, vol.2, p.37. 
a apreensão objetiva das coisas, mas é possível que esse intelecto seja aperfeiçoado e a mudança no conhecimento é capaz de modificar o curso de vida de alguém.

Sabe-se que em Schopenhauer há a noção de caráter inteligível e caráter empírico. O primeiro, inato e imutável, é a essência de um indivíduo; o segundo é a mera manifestação do inteligível. O caráter inteligível é o ser de alguém, é a essência de cada individuo. Ele está fora do tempo, mas aparece no tempo como caráter empírico. Como fenômeno, o caráter se desvela conforme as situações se apresentam. Só é possível conhecer o caráter depois das ações executadas, tanto o dos outros quanto o próprio. O filósofo afirma que:

Cada coisa como fenômeno, como objeto, é absolutamente necessária; no entanto, EM SI mesma é Vontade e esta é integralmente livre por toda a eternidade. O fenômeno, o objeto, é necessária e inalteravelmente determinado na cadeia de fundamentos e consequências, a qual não admite interrupção alguma ${ }^{14}$.

Schopenhauer afirma que "a mesma doutrina da necessidade dos atos de vontade exige que a existência e a essência do homem sejam obra de sua própria liberdade, portanto de sua vontade que então possui asseidade"15. O caráter inteligível é um ato livre por não ter fundamento, por não ter uma causa que o determine. Por isso, pode-se dizer que não há razão ou causa para ser o que somos, como um ato livre da vontade.

O que condiciona as ações humanas é a relação entre motivo ${ }^{16}$ e caráter. Em Sobre o fundamento da moral, Schopenhauer aponta três tipos de caracteres: o egoísta, que quer tudo para si e não vê na vontade alheia um empecilho para sua ação, por isso é capaz de ações injustas; o maldoso, que têm no sofrimento alheio uma fonte de prazer, podendo chegar a agir cruelmente; e o compassivo, que pode ser justo, caso o respeito à vontade de outrem seja um empecilho para ações injustas, ou caridoso, quando é impelido a ajudar ao ver o sofrimento alheio ${ }^{17}$. Essa diferença entre os caracteres

14 SCHOPENHAUER, O mundo como vontade e representação, tomo II, p.372.

15 SCHOPENHAUER, Sobre a ética (Parerga e paralipomena), p.81.

16 “O motivo pode ser definido como um estímulo externo, cuja ocasião gera uma imagem no cérebro, sob cuja mediação a vontade realiza o efeito propriamente dito, a ação corporal” (SCHOPENHAUER, Sobre a vontade na natureza, p.68).

17 Cf. SCHOPENHAUER, Sobre o fundamento da moral, p. 195 
determina como cada indivíduo reagirá às circunstâncias a que forem expostos. Cada tipo de caráter possui uma sensibilidade preponderante para determinados motivos:

As três motivações morais dos homens, o egoísmo, a maldade e a compaixão, estão presentes em cada um numa relação incrivelmente diferente. Conforme esta for, os motivos agirão sobre ele e as ações acontecerão. Sobre um caráter egoísta só terão força os motivos egoístas, e tanto os referentes à compaixão como os referentes à maldade não lhe serão superiores ${ }^{18}$.

O mesmo motivo recebe respostas diferentes dependendo do caráter em que atua. Cada indivíduo manifesta seu caráter com necessidade, respondendo de maneira determinada aos motivos dados. Um motivo pode não ser notado por um indivíduo de um determinado caráter enquanto para outro pode ser respondido com veemência. Para que certas características se tornem conhecidas são necessários motivos que as façam vir à tona. Sem a exposição a uma situação que possa desencadear certos aspectos do caráter que ainda estão ocultos eles não podem ser conhecidos.

Ninguém se torna isto ou aquilo por mais que queira sê-lo, mas seu agir procede de seu caráter inato e imutável, é determinado de modo mais próximo e específico pelos motivos e consequentemente é o produto destes dois fatores ${ }^{19}$.

Ao observarmos nossas ações diante dos motivos dados podemos perceber quem somos. Só conhecemos determinados aspectos de nosso caráter, até que uma ocasião traz à tona outros que ainda não haviam sido revelados. Por vezes, pensamos conhecer alguém e ficamos surpresos com suas atitudes. No entanto, não houve qualquer mudança em seu caráter, e sim, a revelação de alguma característica até então desconhecida por nós. Podemos nos surpreender até mesmo conosco, quando achamos que agiríamos de uma maneira ao vivenciar uma situação e quando a ocasião surge agimos de forma completamente diferente da que esperávamos. No §118 de Parerga e paralipomena, Schopenhauer expõe:

A imutabilidade do caráter e a necessidade das ações que dela procedem se apresentam com uma clareza incomum naquele que em uma oportunidade qualquer não se comportou como devia, por falta de decisão, firmeza, coragem ou qualquer outra propriedade requerida pelo momento. Na sequência,

18 Ibidem.

19 SCHOPENHAUER, Sobre a ética (Parerga e paralipomena), p. 74, 75. 
ele reconhece e lamenta sinceramente seu ato incorreto, e pensa: "Se estivesse novamente na mesma situação, agiria de modo diferente!” A situação se repete, o mesmo caso se lhe apresenta, mas ele procede do mesmo modo - para seu grande espanto ${ }^{20}$.

De acordo com Schopenhauer, nos enganamos ao pensar que existe a possibilidade de escolher entre uma coisa ou outra quando determinada situação se apresenta. Esse engano se dá porque cada um se considera livre e pensa ser possível decidir suas ações em qualquer caso dado, mas, com a reflexão sobre o ocorrido, o indivíduo pode reconhecer que do confronto do caráter com os motivos sua ação não poderia ter sido outra ${ }^{21}$.

No \$55 d’O mundo como vontade e representação, Schopenhauer afirma que a "decisão eletiva”, suposta vantagem do homem em relação aos animais ${ }^{22}$, é vista por alguns “como uma liberdade da vontade em atos individuais”. Mas isso se deve aos motivos que, dispostos abstratamente, conflitam entre si até que o mais forte determine a escolha. É a isso que alguns atribuem a liberdade, por desconsiderar o impulso determinado que serve de base ao intelecto ${ }^{23}$. A deliberação consiste na possibilidade que o homem tem de trazer os motivos ao intelecto, na ordem que lhe for conveniente, e dispô-los no "tribunal da sua vontade". A capacidade de deliberar torna o campo de escolhas do homem muito maior que o dos animais, que só possuem a impressão presente. A independência “do constrangimento imediato dos objetos presentes” é o que proporciona ao homem uma liberdade relativa e comparativa ${ }^{24}$. O filósofo alerta: “de modo algum a decisão eletiva deve ser vista como liberdade do querer individual,

20 SCHOPENHAUER, Sobre a ética (Parerga e paralipomena), p. 76.

21 Cf. SCHOPENHAUER, O mundo como vontade e representação, tomo I, p.374.

22 Essa capacidade da razão de considerar não apenas a impressão do presente, mas passado e futuro, também pode ser vista como um fator que contribui para o sofrimento muito maior no homem do que no animal, como confirma a seguinte passagem: "Ademais, semelhante capacidade de deliberação no homem também pertence às coisas que tornam a sua existência tão mais atormentada que a do animal; pois em geral nossas grandes dores não se situam no presente, como representações intuitivas ou sentimento imediato, mas na razão, como conceitos abstratos, pensamentos atormentadores, dos quais os animais estão completamente livres, pois vivem apenas no presente, portanto num estado destituído de preocupação e digno de inveja" (SCHOPENHAUER, O mundo como vontade e como representação, $1^{\circ}$ tomo, p.385, 386).

23 Cf. SCHOPENHAUER, O mundo como vontade e representação, tomo I, p.385.

24 SCHOPENHAUER, A. O livre arbitrio (Sobre a liberdade da vontade), p.75. 
isto é, a independência da lei da causalidade, cuja necessidade estende-se tanto sobre os homens quanto sobre todos os outros fenômenos"25.

O intelecto se esforça para esclarecer os motivos antes de uma suposta decisão. A razão fala em favor de uma escolha, a inclinação em favor de outra. Mesmo que pareça ser possível em uma dada situação duas decisões opostas, o intelecto é o mero espectador que acredita participar da escolha quando a vontade já determinou como o individuo agirá quando a ocasião surgir.

No \$20 de Sobre o fundamento da moral, Schopenhauer se dedica a responder à seguinte pergunta: “em que repousa a tão grande diferença no comportamento moral dos homens?" O filósofo inicia sua resposta afirmando que “a diferença ética dos caracteres é inata e indelével" 26 e que a tentativa de ensinar é ineficaz para mudar um caráter. Pelo ensinamento alguém pode mudar suas ações, por ser convencido de que não utilizou os meios mais adequados para atingir seus fins, mas continuará a querer aquilo que sempre quis. Os atos de um indivíduo podem variar muito no decorrer de sua vida, mas essa mudança é atribuída ao conhecimento e não à vontade. Com a mudança no conhecimento, um indivíduo pode mudar os meios para atingir seus objetivos que permanecem os mesmos.

Na experiência vemos as mesmas pessoas praticando atos bem diversos ao longo de suas vidas. Se a modificação do caráter é impossível, a que se deve tantas mudanças de comportamento no decorrer da vida de alguém? Por que vemos algumas pessoas reagirem de uma maneira diferente às circunstâncias muito semelhantes se a relação entre motivo e caráter se dá de forma necessária? É possível ver uma pessoa de caráter egoísta ajudando a outrem e um maldoso se privando de causar o mal. Podemos concluir que houve mudança nesses caracteres? Schopenhauer dá uma resposta negativa a essa questão, atribuindo a mudança ao conhecimento e não ao caráter. Se um egoísta passa a acreditar que doando seus bens receberá em dobro no futuro, ele pode considerar ser um bom investimento doá-los. Seu objetivo não mudou, e sim os meios para alcançá-los. Se antes acreditava que guardando seria capaz de acumular uma grande fortuna, agora acredita que doando chegará ao seu objetivo com mais facilidade. Ele passa a pensar

25 SCHOPENHAUER, O mundo como vontade e representação, tomo I, p.389.

26 SCHOPENHAUER, Sobre o fundamento da moral, p.19o. 
nisso como um investimento que trará um retorno muito maior do que se não o fizesse. Um egoísta pode se privar de cometer injustiças, mesmo quando sua vontade o inclina para isso, por achar que uma boa reputação com os que com ele convivem pode lhe trazer mais vantagens que a que pode obter com sua injustiça.

[...] se agora, em ocasião similar, age de maneira diferente, isto se deve ao fato de as circunstâncias serem outras, a saber, segundo a parte delas que depende do seu conhecimento, embora pareçam ser as mesmas. - Contudo, se de um lado o desconhecimento das circunstâncias reais pode retirar-lhe a eficácia, de outro as circunstâncias totalmente imaginárias podem fazer efeito igual ao das reais, não só no caso de uma ilusão particular, mas também no geral e duradouramente ${ }^{27}$.

Mesmo que as ações pareçam ter mudado completamente, as finalidades continuam sendo as mesmas. Um egoísta continua visando o próprio bem, o maldoso o mal alheio e o compassivo o bem de outrem. Alguém pode ser convencido, pelo ensinamento, de que não utilizou os meios mais adequados para atingir seus fins e mudar suas ações a partir desse conhecimento, mas não deixará de querer o que antes queria. Apesar de pensar ser o responsável pelas decisões, o intelecto apenas dispõe os motivos tentando esclarecê-los, quando a vontade já determinou qual ação será realizada no caso. Ele é um mero espectador, que acredita poder decidir livremente entre um motivo e outro, quando a resposta final é determinada pela vontade. O filósofo afirma que

[...] mesmo quando o intelecto laboriosamente ponderou e ruminou, para finalmente produzir a partir de inúmeros dados por meio de combinações difíceis o resultado que parece mais de acordo com os interesses da vontade. Enquanto isso, a vontade ficou à toa repousando; após o resultado ser alcançado, ela entra em cena, como o sultão faz no divã, apenas para expressar mais uma vez a sua monótona aprovação ou desaprovação. É verdade que isso pode ocorrer em graus variados, mas em essência permanece sempre a mesma coisa ${ }^{28}$.

Quando surge um motivo o intelecto tenta direcionar a vontade pelo melhor caminho para a sua satisfação. Ele não pode fazê-la mudar seu alvo, mas é possível sugerir outros meios para os mesmos fins. O intelecto realiza uma mediação entre os motivos e a vontade individual. O que diferencia o homem dos demais animais é a razão, ou seja,

27 SCHOPENHAUER, O mundo como vontade e representação, tomo I, p.382.

28 SCHOPENHAUER, O mundo como vontade e representação, tomo II, vol.1, p.315. 
a capacidade de elaborar conceitos, que são representações de representações. Pela razão é possível passar das representações intuitivas para as abstratas, que podem atuar como motivos imaginários sobre a vontade.

Enquanto, de fato, o animal é sempre motivado apenas por uma representação intuitiva, o homem, ao contrário, esforça-se em excluir completamente esse tipo de motivação, ao procurar determinar-se exclusivamente por motivos abstratos, utilizando assim sua prerrogativa da razão em vista da maior vantagem possível e, independente do momento presente, não escolhe nem foge da fruição ou da dor passageiras, mas pondera as consequências delas ${ }^{29}$.

Quando um motivo externo se apresenta, o intelecto humano pode evocar situações passadas e criar representações abstratas que levam à previsão do futuro. Se, no passado, um motivo semelhante se apresentou, a vontade respondeu de tal maneira e a consequência foi desastrosa, quando o mesmo motivo se apresentar o intelecto pode evocar aquela situação anterior e mostrar que se a resposta for a mesma de antes a consequência também será. Ou então, criar mentalmente certas situações que podem favorecer ou impedir certas reações volitivas. Dessa forma, a experiência leva ao aperfeiçoamento do conhecimento e faz com que a ação não seja a mesma de antes, mesmo que a vontade não tenha mudado.

Não apenas o conhecimento do mundo exterior, mas a consciência de si mesmo é tarefa do intelecto. O caráter de alguém pode se tornar conhecido depois das ações realizadas. Ao observar suas atitudes em certas situações, um indivíduo passa a conhecer seu caráter e prever as ações futuras. Com isso, seu intelecto pode formular representações a fim de direcionar suas próprias ações para utilizar meios diferentes dos que foram empregados anteriormente. Imaginando as consequências para determinados atos um indivíduo pode agir de outra forma para chegar ao que quer.

Podemos inferir que, sendo o caráter empírico determinado pelo inalterável caráter inteligível, é vão tentar melhorar certos aspectos do próprio caráter ou evitar as más inclinações e deixar-se levar por todos os impulsos? A resposta de Schopenhauer é negativa. Quando dizemos que alguém tem ou não caráter, estamos nos referindo ao que o filósofo chama de caráter adquirido. O caráter adquirido é o conhecimento da própria individualidade. É por meio dele que o homem pode conduzir sua vida da for- 
ma mais adequada, consciente do que quer e pode fazer. Mas, quem não se conhece, não sabe o que pode executar, permanece vagando sem rumo, buscando coisas que não diminuem sua insatisfação ou dirige sua vida de uma maneira diferente da que o faria se sentir menos infeliz. Muitas vezes pode se confundir e tentar fazer aquilo que é possível ao homem em geral, mas não cabe à sua individualidade. Dessa forma, tenta fazer de sua vida uma superfície, ao invés de uma linha reta, tentando abraçar todas as possibilidades sem uma direção ${ }^{30}$. Somente com o conhecimento da própria natureza o homem adquire aquilo que é comumente chamado de caráter, capaz de livrá-lo de pretensões e descontentamentos.

Isso nos coloca na condição de agora guiar, com clareza de consciência e metodicamente, o papel para sempre invariável de nossa pessoa, que antes naturalizávamos sem regra, e preencher, segundo a instrução de conceitos fixos, as lacunas provocadas por humores e fraquezas [...] Apenas quem alcançou semelhante estado sempre será inteiramente a si mesmo com plena clareza de consciência e nunca trairá a si nos momentos cruciais, já que sempre soube o que podia esperar de $\mathrm{si}^{31}$.

Conforme o indivíduo se conhece, sabe o que pode esperar de si. Por vezes, uma pessoa tenta fazer coisas que estão fora de suas possibilidades, contrárias à sua natureza, e não consegue o sucesso nessas tentativas. Quanto mais preciso for o conhecimento da própria individualidade, melhor será sua condução na vida, evitando se esforçar por aquilo que não possui aptidão e se empenhando somente no que sabe que pode obter êxito ${ }^{32}$.

Se tivermos conhecido distintamente de uma vez por todas tanto nossas boas qualidades e poderes quanto nossos defeitos e fraquezas, e os tenhamos fixado segundo nossos fins, renunciando contentes ao inalcançável; então nos livramos da maneira mais segura possível, até onde nossa individualidade o permite, do mais amargo de todos os sofrimentos, estar descontente consigo mesmo,

30 Cf. Idem, p.392, 393 .

31 SCHOPENHAUER, O mundo como vontade e representação, tomo I, p.394.

32 É nos Aforismos para a sabedoria de vida que Schopenhauer melhor desenvolve sua eudemonologia, indicando formas de "conduzir a vida do modo mais agradável e feliz possível" (SCHOPENHAUER, A. Aforismos para a sabedoria de vida, p.1). 
consequência inevitável da ignorância em relação à própria individualidade, ou da falsa opinião sobre si, e presunção daí nascida 33 .

O desconhecimento do próprio caráter pode levar o indivíduo a presunção de achar que pode fazer mais do que lhe é possível de fato, a desejar a posição ocupada por outro e à completa falta de habilidade em conduzir sua vida. Por isso, o caráter adquirido é de grande utilidade, sobretudo para a vida no mundo.

Com a possibilidade de condução da vida, aberta pelo conhecimento da própria individualidade, Schopenhauer aponta um caminho de rejeição ao fatalismo, mesmo diante da impossibilidade de mudança daquilo que somos. Chevitarese afirma que “ainda que o intelecto não possa transformar a vontade ou decidir em seu nome, pode ele, entretanto, contribuir para uma mudança na canalização de nossos esforços, alterando significativamente a conduta"34. Dessa forma, o indivíduo pode aproximar-se do contentamento em relação ao próprio ser. O intelecto soma-se ao caráter na definição das ações humanas pela sua capacidade de sugerir motivos abstratos à vontade, para que se busque o que se quer da melhor maneira possível. Caráter e intelecto são “aliados” na produção das ações. Se um determina qual será a reação aos motivos dados o outro seleciona os motivos que se apresentarão ao primeiro.

33 SCHOPENHAUER, O mundo como vontade e representação, tomo I, p.396.

34 CHEVITARESE, L. "A eudemonologia empírica de Schopenhauer: a "liberdade que nos resta" para a prática de vida”. In: REDYSON, Deyve (org.). Arthur Schopenhauer no Brasil: em memória dos 150 anos da morte de Schopenhauer, p. 132, grifo do autor. 


\section{REFERÊNCIAS BIBLIOGRÁFICAS}

BARBOZA, Jair. Schopenhauer: a decifração do enigma do mundo. São Paulo: Moderna, 1997.

CHEVITARESE, Leandro. "A eudemonologia empírica de Schopenhauer: a "liberdade que nos resta” para a prática de vida”. In: REDYSON, Deyve (org.). Arthur Schopenhauer no Brasil: em memória dos 150 anos da morte de Schopenhauer. João Pessoa: Ideia, 2010. p.127-146.

SCHOPENHAUER, Arthur. O mundo como vontade e como representação, $1^{\circ}$ tomo. Tradução de Jair Barboza. São Paulo: Editora UNESP, 2005.

. O mundo como vontade e como representação, tomo II: complementos, volumes 1 e 2. Tradução de Eduardo Ribeiro da Fonseca. Curitiba: Ed. UFPR, 2014. . Sobre o fundamento da moral. Tradução de Maria Lúcia Mello Oliveira Cacciola. São Paulo: Martins Fontes, 2001.

- Sobre a Filosofia e seu método. Tradução brasileira dos capítulos 1 a 7 de Parerga e Paralipomena. Tomo II. Flamarion Caldeira Ramos. São Paulo: Hedra, 2010. . Sobre a Ética. Tradução brasileira dos capítulos 8 a 15 de Parerga e Paralipomena. Tomo II. Flamarion Caldeira Ramos. São Paulo: Hedra, 2012.

. Sobre a vontade na natureza. Tradução de Gabriel Valladão Silva. Porto Alegre: L\&PM, 2013.

O livre arbítrio.Tradução brasileira de Sobre a Liberdade da Vontade. Lohengrin de Oliveira. SP: Ediouro, s.d. - Aforismos para a sabedoria de vida. Tradução de Jair Barboza. São Paulo: Martins Fontes, 2006. 